Volume 10. No. 1

May - July 2016

\title{
i-manager's
}

\section{Journal on Educational Psychology}

An attempt to explore the mental mechanism of teaching and learning 


\title{
i-manager's
}

\section{Journal on Educational Psychology}

\author{
Editor-in-Chief \\ Joe Winston \\ EDITORIAL COMMITTEE
}

\begin{abstract}
Dr. Mahender Reddy Sarsani
\end{abstract}
Dr. Jean Mandernach

Prof. Laura Rader

Dr. Lence Miloseva

Dr. Jan D. Sinnott

\author{
Professor of Education, \\ University College of Education, \\ Kakatiya University, \\ Warangal (AP), \\ India. \\ Associate Professor of \\ Psychology \& Online learning, \\ Grand Canyon University. \\ Assistant Professor, \\ Program Director, \\ Special Education Programs, \\ The City College of the University \\ New York.
}

Full Professor, Faculty of Medical Science Goce Delcev University, Macedonia.

Psychology Department, Towson University,
Dr. Denise Winsor

Dr. Sarwat Sultan

Dr. Stacey Takanishi

Dr. Abhishek Kumar Srivastava
Assistant Professor of Counseling, Educational Psychology \& Research, University of Memphis, Memphis. Department of Applied Psychology, Bahauddin Zakariya University, Multan, Pakistan.

Instructor and Field Supervisor, University of Hawaii at Manoa,

Hawaii.

Assistant Professor, Faculty of Disability Management and Special Education, Ramakrishna Mission Vivekananda University, Tamil Nadu, India.

\section{Our Offices}

Publication Office: 13B, Popular Building, Mead Street, College Road, Nagercoil - 629001.

Registered Office: 3/343, Hill View, Town Railway Nager, Nagercoil, Kanyakumari Dist., Tamilnadu, India - 629001. 


\section{i-manager's}

\section{Journal on Educational Psychology}

\section{About the Journal}

i-manager's Journal on Educational Psychology delves into the intricacies of the creative mind with a core of useful resources and unfolds the different teaching learning processes and the varied interests of students in a psychological perspective. The Journal facilitates younger generation with scientific and cognitive insights and improves the overall quality of education. The incessant quest in the field of education, the attempts made to understand the theories of learning and the factors required for successful learning outcome provide the best ground for the researchers to explore the teaching and learning process psychologically.

\section{OUR TEAMS}

$\begin{array}{lr}\text { Renisha Winston } & \text { Editorial Director } \\ \text { J. Cibino Pearlsy Ross } & \text { Editorial Support } \\ \text { Venkadesan S } & \text { Issue Editor } \\ \text { R. Anish } & \text { Designer } \\ \text { Centhil Lakshmi Priya P.G } & \text { GM - Operations } \\ \text { Anitha Bennet } & \text { GM - Subscriptions } \\ \text { Manikandan V } & \text { Production Manager }\end{array}$
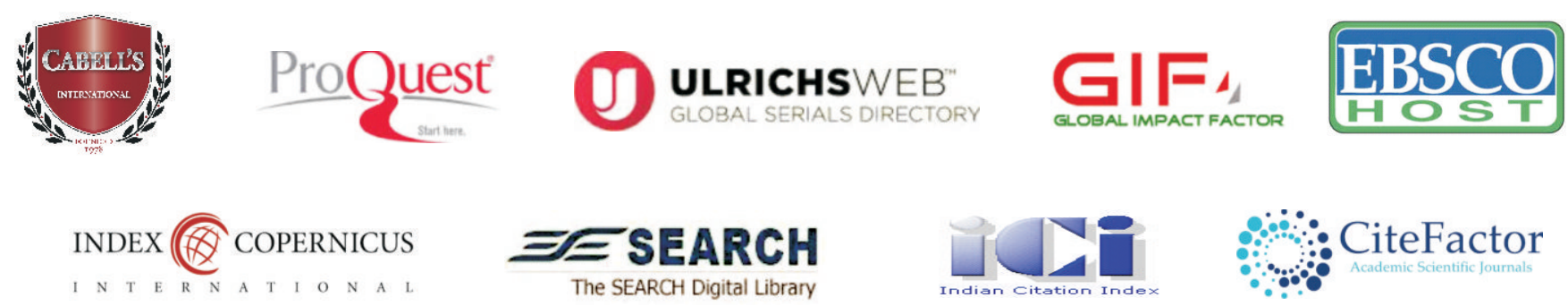


\section{RESEARCH PAPERS}

A CASE OF DEPRESSION SCREENING IN SCHOOLS

By Lence Miloseva

BURNOUT AMONG THE COUNSELING PROFESSION: A SURVEY OF FUTURE PROFESSIONAL COUNSELORS

By Elizabeth Ann Wardle, Mary G. Mayorga

EXPLORING ELEMENTARY STUDENT PERCEPTIONS OF WRITING FEEDBACK

By Sarah Marrs, Sharon Zumbrunn, Caitlin Mcbride, JK Stringer

EMOTIONAL, SOCIAL, EDUCATIONAL ADJUSTMENT OF HIGHER SECONDARY SCHOOL STUDENTS IN RELATION TO ACADEMIC ACHIEVEMENT

By J. Master Arul Sekar, A.S. Arul Lawrence ERA 
The way of learning and educating students is transforming by the developmental stages of Education system. Especially the school education system has different kinds of approaches to teaching as well as learning. To highlight the difficulties and challenges faced by these people, the current issue of i-manager's Journal on Educational Psychology covers the contents under School Educational Psychology. This issue significantly provides focus on where the learning communities feel inadequacy in learning and how it can be changed.

Lence Miloseva has presented a study about the screening of subclinical depression in adolescents ranging from 13 to 17 years of age in primary and secondary schools. The sample selected for the study is 412 respondents. A structured list of data questionnaire, M.I.N.I. kid interview and Centre for Epidemiological Depression Scale were used as instruments for data collection and the data were analyzed using the computer program SPSS 18.0. The result obtained provide practical implication for designing preventive and intervention programs in schools.

Elizabeth Ann Wardle and her co-author Mary G. Mayorga have conducted a study to determine if Master's level counseling students demonstrated the possible indicators of burnout. The study consists of 94 participants and a nonexperimental design was used in this investigation to obtain quantitative data. A single survey instrument was distributed through electronic mail, utilizing the online computerized program. The results show that, over $85 \%$ of the participants in this study have some degree of indication of burnout.

Sarah Marrs and her co-authors have presented a study to explore the ways in which young writers perceive feedback on their writing. The sample consists of 867 students in grades 3 - 5 across four elementary schools. An online survey was used for data collection and the participants were asked to respond to the open and closed ended question. The findings of the study highlight the range of both positive and negative views about writing feedback, as well as the power of listening to student voices. The authors recommend that, further studies should be not only to understand the students' perceptions of writing feedback, but also the origins of these perceptions.

Master Arul Sekar and his co-author Arul Lawrence have conducted a study to investigate the relationship between adjustment and academic achievement of higher secondary school students. The sample consists of 350 higher secondary school students selected from ten schools. Adjustment Inventory developed by A.K.P. Sinha and R.P. Singh and academic achievement constructed by the investigators are used as tools and the survey methodology was adopted for the study. The finding showed that, there is a significant relationship between emotional, social, educational adjustment of higher secondary school students in relation to academic achievement.

Sumitha and her co-author Rexlin Jose have presented a study to find out the problem solving skill of early adolescents based on their gender, type of family and the problem solving skills. 100 early adolescents were randomly selected for the study and survey method was adopted for the study. The investigators used self-made tool to collect data regarding the Problem Solving Skill. The analysis of data showed that, female students are better than the male students, nuclear family students are better than the joint family students in their problem solving skill and type of school does not influence the problem solving skill of early adolescents.

It is our pleasure to step into the first issue of the 10th volume with these essential facets of Educational Psychology and help students face the challenges in their learning difficulties. We hope to sustain the remarkable quality of principles!

Warm Regards,

Venkadesan S.

Associate Editor

i-manager Publications 


\title{
A CASE OF DEPRESSION SCREENING IN SCHOOLS
}

\author{
By \\ LENCE MILOSEVA \\ Full Professor, Faculty of Medical Science, Goce Delcev University, Stip, Macedonia
}

\begin{abstract}
Adolescent clinical and subclinical depression has a significant negative impact on adolescents well being, school performance and consequently produces maladaptive outcomes in terms of subsequent education and occupational functioning. This research is a part of a larger research project with a focus on clinical and subclinical depression during adolescence. So far there has been no other study conducted with adolescents in Macedonia, whose research subject was subclinical depression and its screening in schools. This was an additional motivation for this research. The objective of this research was to introduce a procedure for selecting and grouping of the research sample and the screening of subclinical depression in adolescents ranging from 13 to 17 years of age in primary and secondary schools that was carried out in the Eastern, Central and Western part of Macedonia in the period of two and a half years. The final sample consisted of the clinical group, 139 (33.7\%) respondents; the subclinical group, 133 (32.3\%) respondents, and 140 (34.0\%) respondents in the control group, and a total of 412 respondents. We believe that the first step in preventing clinical depression development in adolescents, including school context, is screening and facing the existence of subclinical depression, on the continuum of the psychological model of depression. The data obtained should have a practical implication for designing preventive and intervention programs in schools.
\end{abstract}

Keywords: Screening, Subclinical, Depression, Adolescent, Schools.

\section{INTRODUCTION}

Depressive disorders often start in adolescence, they have a chronic course often with relapses and remissions in adulthood. The etiology of depression in children and adolescents involves a complex interaction of genetic, neurobiological, cognitive, interpersonal and environmental factors, together with development factors (Rao \& Chen, 2009; Sander, Herren, \& Bishop, 2015). Subclinical depression is not less important. Between $20 \%$ and $50 \%$ of adolescents has experience with subsyndromal depression levels (Kessler, Avenevoli, \& Merikangas, 2001; Hankin, 2006; Cuijpers, van Straten, \& Smit, 2007; Cuijpers, Sander, Koole, van Dijke, Roca, Li, \& Reynolds III, 2014). Although a large number of adolescents experience subclinical levels of depression, they are seldom involved in research, preventive or intervention programs (Gotlib, Lewinsohn, \& Seeley, 1995; Gotlib \& Hammen, 2014). This was the main motive, the challenge and the starting point for reflection on the importance and justification for taking up this topic.
According to Cuijpers and associates (Cuijpers, De Graaf, \& Van Dorsselaer, 2004), individuals are considered to have subclinical depression when they manifest clinically relevant depressive symptoms, but they do not meet standard diagnostic criteria for depressive disorders defined according to the DSM (Diagnostic and Statistical Manual of Mental Disorders) classification (American Psychiatric Association, 1994 and 2000), at least one of the basic symptoms of depression, as well as one additional other symptom, but not more than a total of four symptoms, or those who have a score above the cutoff level on the self-reporting depression scale, until the criteria for a depressive disorder according to the diagnostic interview is met.

The researchers have used this criterion in this research, with the cut-off score of 16 on Centre for Epidemidogical Depression Scale (CES-D), or through scoring above the cut-off score and without meeting the criteria for a full clinical picture of Major Depression (MDD), on the basis of the diagnostic interview M.I.N.I. kid (M.I.N.I. kid screen 


\section{RESEARCH PAPERS}

/DSM-IV - TR/ (Sheehan \& Lecrubier, 2001/2006). Please note that not for a moment psycho-diagnosing according to the diagnostic classification was not only the goal of this study, but it was determining a research group with subclinical depression on the continuum of depression, according to the psychological model of depression. Subclinical depression is important from a clinical perspective, not only because the person may be in a state that necessitates treatment, but because it is associated with the risk of developing major depression that can be prevented or mitigated with treatment.

Adolescent clinical and subclinical depression has a significant negative impact on adolescents' well being, school performance and consequently produces maladaptive outcomes in terms of subsequent education and occupational functioning. Some researchers emphasis that, several key symptoms of depression, such as psychomotor retardation, poor initiative, impaired ability to concentrate, low self-esteem, sense of worthlessness, and social withdrawal may significantly impair cognitive functioning and performance and diminish initiative in learning (Kirkcaldy \& Siefen, 1998; Fröjd et al., 2008). Negative social feedbacks from teachers and poor social relationships with peers may also contribute to learning problems through paying attention to the depressed adolescent's behavior and emotional problems instead of learning. According to Fröjd et al. (2008), depressed young people had impaired abilities to cope with academic responsibilities.

Screening for depression is an important component in the implementation of a comprehensive mental health system in the schools. The authors believe that, the first step in preventing clinical depression development in adolescents, including school context, is screening and facing the existence of subclinical depression, on the continuum of the psychological model of depression. From a clinical point of view, subclinical depression is important for two reasons. First, subclinical depression is often a non-validating state with significant psychological suffering and need for treatment. The goal of treatment is to reduce depressive symptoms and improve quality of life. Another reason why subclinical depression is important from the clinical point of view is an increased risk of developing major depression.

Stice, Shaw, Bojon, Marti, and Rohde (2009) in their metaanalytical review of depression prevention programs for children and adolescents found that prevention programs that targeted high-risk adolescents produced larger effects than did programs that were universal.

According to systematic review conducted by Thombs, Roseman, \& Kloda (2012), the authors know very little about potential benefits of depression screening in childhood versus potential harms. The proposed systematic review could determine whether there is sufficient evidence to support screening. The conclusions drawn from the review could help not only to researchers, but also to policy-makers, health care providers and will allow decisions to be made about whether screening programs are likely to benefit children and adolescents.

\section{Material and Methods}

\section{Objectives}

This research is a part of a larger research project with a focus on clinical and subclinical depression during adolescence. So far there has been no other study conducted with adolescents in Macedonia, whose research subject was subclinical depression and its screening in schools. This was an additional motivation for this research.

The objective of this research was to introduce a procedure for selecting and grouping of the research sample and the screening of subclinical depression in adolescents ranging from 13 to 17 years of age in primary and secondary schools that was carried out in the Eastern, Central and Western part of Macedonia in the period of two and a half years. The data obtained should have a practical implication for designing preventive and intervention programs in schools.

\section{Instruments}

In order to asses data, the authors applied the List of data; M.I.N.I. kid interview (Sheehan \& Lecrubier, 2001/2006) and Centre for Epidemiological Depression Scale (CES-D, NIMH (National Institute of Mental Health), Radloff, 1977). 


\section{RESEARCH PAPERS}

The List of data is a structured questionnaire designed for this research for all respondents, and it contains information on: gender, age, education, place, diagnosis (for clinical sample only), and the average school success. Questions about whether they have ever visited a psychiatrist/psychologist and what the reason was for it were also on the list. M.I.N.I. kid interview is a structured clinical interview for diagnosis screening according to DSM-IV-TR (Diagnostic and Statistical Manual of Mental Disorders (4th ed. Text Revision)) classification, the version for adolescents (Sheehan \& Lecrubier, 2001/2006).

The presence and level of depressive symptoms are operationalized through Centre for Epidemiological Depression Scale (CES-D, NIMH, Radloff, 1977). Total score of 16 or higher is considered depressed. The CES-D is a 20item instrument developed by NIMH, Radloff (1977), to detect major or clinical depression in adolescents and adults in community samples. The CES-D includes twenty items comprising six scales reflecting major facets of depression: depressed mood, feelings of guilt and worthlessness, feelings of helplessness and hopelessness, psychomotor retardation, loss of appetite, and sleep disturbance. Scores range from 0-60, with depressive symptomatology indicated at a cut-off of 16 or above, as the authors used in this research as well. The CES-D has been shown to be a good reliable measure for assessing the number, types, and duration of depressive symptoms with high internal consistency (Radloff, 1977). According to the pilot study conducted on the Macedonian sample, good measures of internal consistency are confirmed $(\alpha=89)$.

\section{Findings of the Present Study}

\section{Sampling Procedure and Procedure of Screening}

After receiving the approval of the Institutional Ethics Committee, the research was planned and conducted in accordance with the provided ethical procedures and codes of psychological research, in clinics and schools in the three main centers of socio-demographic regions in the Republic of Macedonia (Shtip, Eastern region; Skopje, Central Region; Bitola, Western region). According to ethical procedure, all participants agree to be involved in the research with guaranteed anonymity and signed informed consents.

For the purposes of this project, the sampling procedure was carried out in the next two phases. In the first phase (pilot study) for the purpose of checking the instruments reliability (Cronbach alpha coefficient) on the non-clinical sample of adolescents between the ages of 13-17 years, a sample of 300 adolescents of both sexes in primary school (grade 7 and 8) and high school (I, II, III year) in Skopje was planned. Of the total 300 planned adolescents, the pilot study took into consideration the data of 282 adolescents. The instruments showed good psychometric properties (more details on this in the previous section on instruments).

In the second phase, for the purposes of the main research, the draft study planned a clinical sample of 150 adolescents between the ages of 13-17 years in Macedonia, 50 in each of the following centers: Shtip, Skopje and Bitola (Figure 1). The main research took place between January 2012 and August 2014. The criterion for inclusion in this pattern is to meet the diagnostic criteria DSM-IV-TR / DSM-V (APA, 2000; 2013) for unipolar depressions without psychotic features (Major Depression,

Clinical Sample in Research
Clinical sample according to draft plan 150
150 (50 from each of the three Clinical centers)
Final Clinical Sample in Research
139 (from three Clinical Centers: Shtip, Skopje and Bitola) (of the planned
150, there were 11 incomplete sets of instruments)

Figure 1. Presentation of the Clinical Sample in the Research

\begin{tabular}{|c|c|}
\hline \multicolumn{2}{|c|}{$\begin{array}{c}180 \text { at the age of } 13 \text { and } 14 \text { years, } 7^{\text {th }} \text { and } 8^{\text {th }} \text { grade of primary school, } 540 \\
\text { at the age of } 15,16 \text { and } 17 \text { years, l, II, III year of high school and secondary } \\
\text { vocational schools. } 240 \text { of each of the three socio-demographic centers } \\
\text { Shtip, Skopje and Bitola, a total of } 720 .\end{array}$} \\
\hline \multicolumn{2}{|c|}{$\begin{array}{l}\text { Of the planned total number of } 720 \text {, due to } 13 \text { incomplete sets of } \\
\text { instruments, for further selection activities } 707 \text { respondents of the control } \\
\text { and subclinical sample were taken into account. }\end{array}$} \\
\hline Clinical Sample & Subclinical Sample \\
\hline $\begin{array}{c}140 \text { respondents } \\
\text { Exclusive criterion } \\
\text { cut-off }<16 \text { on CES-D } \\
\text { M.I.N.I kid }\end{array}$ & $\begin{array}{l}133 \text { respondents } \\
\text { cut-off }>16 \text { on CES-D } \\
\text { M.I.N.I kid }\end{array}$ \\
\hline
\end{tabular}

Figure 2. The selection and grouping procedure of the research sample 
MDD). The data for 139 adolescents were taken into account in the final clinical sample.

A control and a sub-clinical sample of adolescents between the ages of 13-17 years were also provided (Figure 2). These samples were formed from a larger sample of adolescents: 180 from primary schools (grade 7 and 8); 540 from high schools and vocational schools (I, II, III year) in Shtip, Skopje and Bitola. There was a total of 720 adolescents, of which 240 were divided by their socio-demographic center. The final sample for further selection activities (control and subclinical sample) covered only adolescents who had completely filled out instruments, or a total of 707. The cut-off score for subclinical depression, on the CES-D, i.e. the score above which the respondents with subclinical depression are, is determined to be above 16. This cut off score is determined based on literature and world research the number of which is unfortunately very small (Cuijpers \& Smit, 2004; Cuijpers, 2014).

From a total of 707 adolescents, by using the CES-D and the cut-off score for adolescents (score above 16), the researchers formed the sub-clinical sample. The respondents in this sample do not meet DSM-IV-TR / DSM-V criteria for Major depression, but they achieve CES-D scores over 16, as the cut-off score. To this end, the researchers have conducted a screening interview with M.I.N.I. kid interview. If respondents have a score $>16$ on the CES-D, and do not meet the criteria for M.I.N.I. kid interviews for major depression (according to DSM-IV-TR / DSM-V criteria), then enter the sub-clinical sample. The number of respondents who met the criterion for the subclinical sample was 133 adolescents. Of the remaining adolescents who have low scores on the CES$D$, below the cut-off score of subclinical depression, the researchers formed a control sample of adolescents. The exclusive criteria were: the presence of organic and psychotic disorders; somatic diseases; $1 Q$ below 75. In order to get a more refined control sample, the psychologists in schools conducted a screening using M.I.N.I. kid interviews, based on the data obtained from the list of basic data.

For the control sample, all adolescents who answered yes

\begin{tabular}{cccc}
\hline Group & Frequency & Percent & $\begin{array}{c}\text { Cumulative } \\
\text { percent }\end{array}$ \\
\hline Clinical & 139 & 33.7 & 33.7 \\
Clinical & 133 & 32.3 & 66.0 \\
Control & 140 & 34.0 & 100.0 \\
Total & 412 & 100.0 & \\
\hline
\end{tabular}

Table 1. Representation of Groups in the Sample (Clinical, Subclinical and Control Group)

to questions pertaining to visiting psychologists/ psychiatrists and the possible reasons for this were interviewed and then, based on the findings, excluded from the sample. The number of respondents who met the criterion for the control sample was 140 adolescents. So, the final sample consisted of: the clinical group, 139 (33.7\%) respondents; the subclinical group, 133 (32.3\%) respondents, and 140 (34.0\%) respondents in the control group, or a total of 412 respondents.

The research at the clinics was conducted by psychiatrists and clinical psychologists who informed parents and adolescents about the purpose of research and obtained informed consent from them. During diagnosing, in addition to other instruments, the same instruments that were assigned to the non-clinical sample (control and subclinical) were used.

The Description of the Research Sample by Relevant Clinical Characteristics and Socio-demographic Variables: Frequency per Group, Sex, Age and School Average Success

- The description of the research sample by relevant clinical characteristics

Table 1 shows the group of the research sample according to relevant clinical characteristics by frequency and percentage of representation. As it can be seen from this table, out of the total number of respondents in the sample, the frequency of subjects in the clinical group is $139(33.7 \%)$, the frequency of respondents' representation from the subclinical sample is $133(32.3 \%)$, and frequency in the control group is 140 (34.0\%).

Overview and Description of the Sample Structure by Socio-demographic Variables: Frequency per Group, Sex, Age, And School Average Success 


\section{RESEARCH PAPERS}

\begin{tabular}{cccc}
\hline Sex & Frequency & Percent & $\begin{array}{c}\text { Cumulative } \\
\text { percent }\end{array}$ \\
\hline Female & 254 & 61.7 & 61.7 \\
Male & 158 & 38.3 & 100.0 \\
Total & 412 & 100.0 & \\
\hline
\end{tabular}

Table 2. Representation of Respondents in the Sample by Sex

According to Table 2, the representation of female adolescents in the total sample is slightly higher than that of the male respondents (61.7\% vs. $38.3 \%$ ). The number and percentage of respondents in the above-mentioned categories is given.

Respondents in the sample were between the ages of 13 to 17 years. The largest number of respondents in the sample was at the age of 17 (134 or $32.3 \%$ ), followed by the age of 16 ( 124 or $30.1 \%$ ), then at the age of 15 (81 or $19.7 \%$ ), at the age of 14 ( 44 or $10.7 \%$ ), and at the age of 13 (29 or $7.0 \%$ ) (Table 3). The average age of the entire sample was $\mathrm{M}=15.70, \mathrm{SD}=1.22$.

Table 4 provides data on the school average success of the respondents in the sample. As it can be seen, the largest number of respondents-160 has the average success of 4.00 (38.8\%); then 153 respondents with the school average success of $3.00(37.1 \%)$ and the smallest number of 99 respondents with the average of 5.00 (24\%).

\section{Discussion}

The researchers were interested how to identify risk group of adolescents for prevention and school-based depression intervention. In order to answer the research question in this study, the data were statistically analyzed using the computer program SPSS 18.0 (SPSS Inc., 2009). Data analysis included the usual statistical analysis for analyzing the item of reliability (Cronbach alpha coefficient) for the applied tests. In addition to the usual descriptive statistical analysis, it also included the one

\begin{tabular}{cccc}
\hline Age & Frequency & Percent & $\begin{array}{c}\text { Cumulative } \\
\text { Percent }\end{array}$ \\
\hline 13 year & 29 & 7.0 & 7.0 \\
14 year & 44 & 10.7 & 17.7 \\
15 year & 81 & 19.7 & 37.4 \\
16 year & 124 & 30.1 & 67.5 \\
17 year & 134 & 32.5 & 100.0 \\
Total & 412 & 100.0 & \\
\hline
\end{tabular}

Table 3. Representation of Respondents according to Age

\begin{tabular}{cccc}
\hline GPA & Frequency & Percent & $\begin{array}{c}\text { Cumulative } \\
\text { percent }\end{array}$ \\
\hline 3.00 & 153 & 37.1 & 37.1 \\
4.00 & 160 & 38.8 & 76.0 \\
5.00 & 99 & 24.0 & 100.0 \\
Total & 412 & 100.0 & \\
\hline
\end{tabular}

Table 4. The Representation of Respondents by School Average Success (GPA)

factor analysis of variance, ANOVA.

The research results of quantitative differences in relation to the level of depressive symptoms on the CES-D instrument between clinical, subclinical and control group

Table 5 shows information that the researchers considered important for further description of the research sample. They can notice a different significance of the average score on the CES-D instrument in all three groups. The researchers started determining the significance of differences between the three groups in the sample (clinical, subclinical, control) in relation to the level of depressive symptoms on the CES-D instrument. Single factor univariate analysis of the variance, and the differences of the three groups according to the level of depressive symptoms on the CES-D instrument were tested: clinical, subclinical, control. The analysis showed that, there are significant differences $F(2,409)=$ 5527.842; $\mathrm{p}<.001$ ).

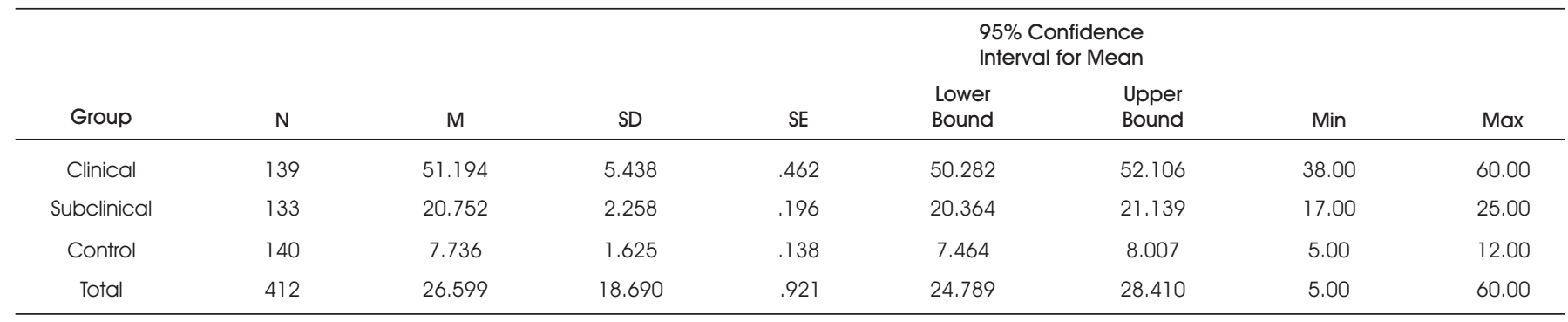

Table 5. Descriptives of Research Samples 


\section{RESEARCH PAPERS}

The researchers wanted to test between which groups there were significant differences, and to this end they started the Scheffe's test of subsequent comparison of groups. Scheffe tests showed that, the differences were significant between all the three groups: depression was most pronounced in the clinical $(M=51.194)$, then in the subclinical $(M=20.752)$ and it was lowest in the control sample $(M=7.736)$, which not only corresponds to the level standards of depression symptoms on the instrument CES-D, but it also speaks in favor of the fact that the groups

\begin{tabular}{cccccc}
\hline CES-D & $\begin{array}{c}\text { Sum of } \\
\text { Squares }\end{array}$ & df & $\begin{array}{c}\text { Mean } \\
\text { Square }\end{array}$ & F & Sig. \\
\hline $\begin{array}{c}\text { Between } \\
\text { Groups }\end{array}$ & 138447.131 & 2 & 69223.566 & 5527.842 & .000 \\
Within Groups & 5121.789 & 409 & 12.523 & & \\
Total & 143568.920 & 411 & & & \\
\hline
\end{tabular}

Table 6. The Significance of Differences between Groups with respect to Levels of Depression Symptoms on the CES-D by using the one-way ANOVA

\begin{tabular}{|c|c|c|c|c|c|c|}
\hline \multirow{2}{*}{$\begin{array}{l}\text { CES-D } \\
\text { Scheffe } \\
\text { (I) group }\end{array}$} & \multirow[b]{2}{*}{ (J) group } & \multirow{2}{*}{$\begin{array}{c}\text { Mean } \\
\text { Differ. } \\
(I-J)\end{array}$} & \multirow[b]{2}{*}{$\begin{array}{l}\text { Std. } \\
\text { Error }\end{array}$} & \multirow[b]{2}{*}{ Sig. } & \multicolumn{2}{|c|}{$\begin{array}{c}95 \% \text { Confidence } \\
\text { Interval }\end{array}$} \\
\hline & & & & & $\begin{array}{l}\text { Lower } \\
\text { Bound }\end{array}$ & $\begin{array}{l}\text { Upper } \\
\text { Bound }\end{array}$ \\
\hline \multirow[t]{2}{*}{ Clinical } & subclinical & $30.442^{\star}$ & .429 & .000 & 29.388 & 31.497 \\
\hline & control & $43.458^{\star}$ & .424 & .000 & 42.418 & 44.499 \\
\hline \multirow[t]{2}{*}{ Subclinical } & clinical & $-30.442^{*}$ & .429 & .000 & -31.497 & -29.388 \\
\hline & control & $13.016^{*}$ & .428 & .000 & 11.963 & 14.068 \\
\hline \multirow[t]{2}{*}{ Control } & clinical & $-43.458^{*}$ & .424 & .000 & -44.499 & -42.418 \\
\hline & subclinical & $-13.016^{*}$ & .428 & .000 & -14.069 & -11.963 \\
\hline
\end{tabular}

${ }^{*} \mathrm{p}<0.001$

Table 7. Multiple Comparisons between groups-Scheffe Post hoc Test

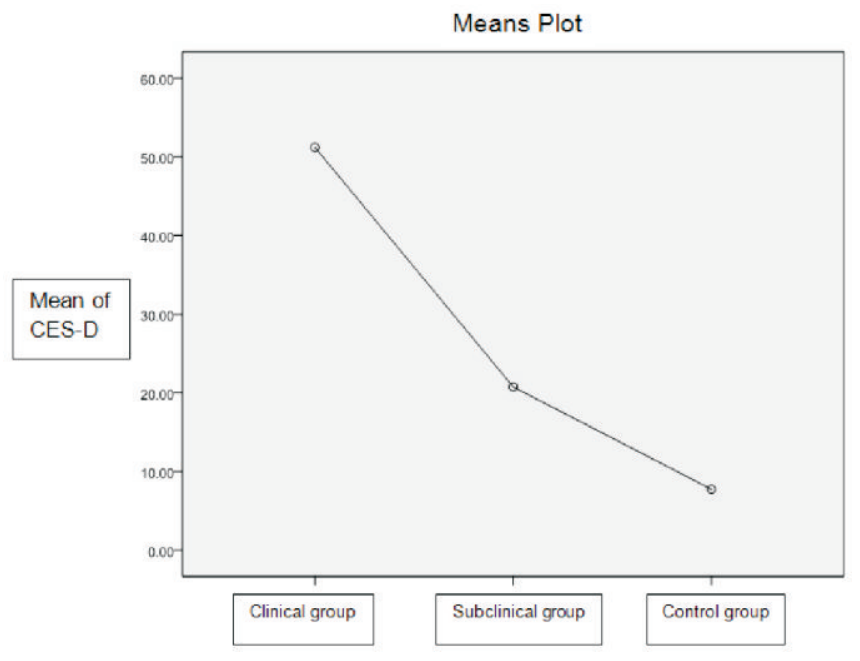

Figure 3. The Significance of Differences in Relation to the Level of Depression Symptoms on the CES-D Instrument between Clinical, Subclinical and Control Group were well-selected by the way of forming the subclinical group with the cut off score $>16$ (Tables 6 and 7) and Figure 3 .

The results of this research could be used in further research that are necessary, especially in the direction of the development of better preventive, diagnostic and therapeutic strategies. The results obtained will give a contribution to the overall scientific knowledge in the field of clinical psychology, which will allow the creation of a specific model for early diagnosis, rational treatment, and with it a better long-term prognosis and improvement of the quality of the life of adolescents, which in addition gives practical meaning to this work.

\section{Conclusion}

These findings seem to have implications for school and mental health professionals in early detection and intervention with depression vulnerable adolescents. From the theoretical-research aspect, the contribution of this paper is the emphasis of the necessity of complementary and integrated approach, as well as of the necessity of strengthening the developmentalpsychological and psychopathological perspective in research and the explanation of etiology, appearance, maintenance and repetition of depression in adolescence.

Similarly, the developmental approach emphasizes the importance of the social context, socio-cultural environment in which cognition takes place, as well as the importance of the role of social support, as it is perceived by adolescents, especially in the transition medium and late childhood/early adolescence and early adolescence/late adolescence. Preventive efforts can be selectively targeted at children and adolescents with academic problems. The authors recommended new research in future and research findings from developmental psychological perspective would be an invaluable contribution to a very important goal in this area the development of empirically substantiated approaches in diagnostic and therapeutic strategies and treatment.

Bearing in mind that screening for depression is essential to ensure accurate diagnosis, follow-up, and effective treatment planning, there are many factors and 
recommendations that have to be taken into consideration. Important stakeholders must be involved before the screening takes place. These stakeholders may consist of school administrators, teachers, families, and mental health organizations. Consent must be acquired from students getting assessed, parents/ guardians, and school districts. Then, National strategy and guidelines should be determined for the implementation, compilation, scoring, analysis, and follow-up of the assessment. Screening of mental health problems in schools and school based mental health programs are very important because it has led to increased identification of at risk adolescents, connection of those students to appropriate services, and promotion of positive mental health.

\section{References}

[1]. American Psychiatric Association, (1994). Diagnostic and Statistical Manual of Mental Disorders, 4th edition, Washington, DC.

[2]. American Psychiatric Association (2000). Diagnostic and Statistical Manual of Mental Disorders, DSM-IV -TR (4th ed. Text Revision). Washington, DC.

[3]. Cuijpers, P., De Graaf, R., and Van Dorsselaer S., (2004). "Minor depression: Risk profiles, functional disability, health care use and risk of developing major depression". Journal of Affective Disorders, Vol. 79, pp. 7179.

[4]. Cuijpers P., and Smit F., (2004). "Subthreshold depression as a risk indicator for major depressive disorder: A systematic review of prospective studies". Acta Psychiatrica Scandinavica, Vol. 109, pp. 325-331.

[5]. Cuijpers, P., Smit, F., and Van Straten, A. (2007). "Psychological treatments of subthreshold depression: a meta-analytic review". Acta Psychiatrica Scandinavica, Vol. 115, pp. 434-441.

[6]. Cuijpers, P., Koole, S.L., Van Dijke, A., Roca, M., Li, J., \& Reynolds, C.F. (2014). "Psychotherapy for subclinical depression:meta-analysis". The British Journal of Psychiatry, Vol. 205, pp. 268-274

[7]. Cuijpers, P. (2014). "Towards a dimensional approach to common mental disorder in the ICD-1 1?". Australian \&
New Zealand Journal of Psychiatry, Vol. 48, pp. 481-2.

[8]. Fröjd, A.S., Nissinen,S.E., Pelkonen, U.I.M., Marttunen, J.M., Koivisto, A., \& Kaltiala-Heino, R., (2008). "Depression and school performance in middle adolescent boys and girls". Journal of Adolescence, Vol. 31, pp. 485-498.

[9]. Gotlib, I.H., Lewinsohn, P., and Seeley, J. (1995). "Symptoms versus a diagnosis of depression: Differences in psychosocial functioning". Journal of Consulting and Clinical Psychology, Vol. 63, pp. 90-100.

[10]. Gotlib, I.H., \& Hammen, C. L. (Eds.) (2014). Handbook of Depression. New York: Guilford Press.

[11]. Hankin, B.L. (2006). "Adolescent depression: Description, causes, and interventions". Epilepsy \& Behavior, Vol. 8, pp. 102-114.

[12]. Kirkcaldy B., \& Siefen G., (1998). "Depression, anxiety and self-image among children and adolescents". School Psychology International, Vol. 19, pp. 135-149.

[13]. Kessler, R.C., Zhao, S., Blazer, D.G., and Swartz M. (1997). "Prevalence, correlates, and course of minor depression and major depression in the National Comorbidity Survey". Journal of Affective Disorders, Vol. 45, pp. 19-30.

[14]. Radloff L.S., (1977). "The CES-D scale: A self report depression scale for research in the general population. Applied Psychological Measurements, Vol. 1, pp. 385401.

[15]. Rao, U., and Chen, L.A. (2009). "Characteristics, correlates, and outcomes of childhood and adolescent depressive disorders". Dialogues in Clinical Neuroscience, Vol. 11 , pp. 45-62.

[16]. Sander J.B. Herren, J., \& Bishop J.A., (2015). "Depression". In R. Flanagan, K. Allen \& E. Levine (Eds.), Cognitive and Behavioral Interventions in the Schools, New York: Springer, pp.85-100.

[17]. Stice E., Shaw H., Bohon C., Marti C.N., and Rohde P., (2009). "A meta-analytic review of depression prevention programs for children and adolescents:Factors that predict magnitude of intervention effects". Journal of Consulting and Clinical Psychology, Vol. 77, No. 3, pp. 486-503. 
[18]. Sheehan D.V., \& Lecrubier Y. (2001/2006). M.I.N.I. SCREEN 5.0.0/English version/DSM-IV July/1/06. Florida: University of South Florida-TAMPA, USA.

[19]. SPSS Inc, (2009). PASW Statistics for Windows, Version 18.0. Chicago: SPSS Inc.
[20]. Thombs, D.B., Roseman, M., \& Kloda, A.L. (2012). "Depression screening and mental health outcomes in children and adolescents: a systematic review protocol". Systematic Reviews, Vol. 1, pp. 58.

\section{ABOUT THE AUTHOR}

Lence Miloseva is a licensed clinical psychologist and psychotherapist. She received her first Ph.D. in Developmental Social Psychology and Clinical psychology at University in Skopje. Macedonia. She finished second Doctoral studies and received second Ph.D. in Clinical psychology and Developmental Psychopathology at University of Belgrade, Serbia. As a JFDP fellow, Prof. Lence Miloseva was visiting professor at Louisiana State University, Baton Rouge, USA. She is currently working as a Full Professor at Faculty of Medical Science, Goce Delcev University, Stip, Macedonia. Her primary research areas include Cognitions and Psychopathology; Developmental Neuroscience and CBT and REBT Psychotherapy. She is the author of or coauthor of over 100 publications in referred Journals, author of Textbooks and Monographs.

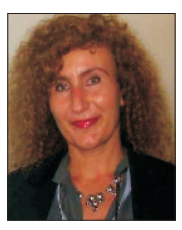




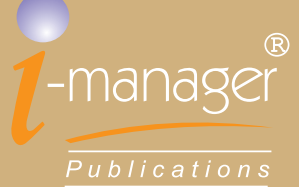

3/343, Hill view, Town Railway Nager, Nagercoil

Kanyakumari Dist. Pin-629 001

Tel: +91-4652-276675, 277675

e-mail: info@imanagerpublications.com 